\title{
Assessment of performance of the Gail model for predicting breast cancer risk: a systematic review and meta-analysis with trial sequential analysis
}

Xin Wang, Yubei Huang, Lian Li, Hongji Dai, Fengju Song ${ }^{*}$ and Kexin Chen ${ }^{*}$

\begin{abstract}
Background: The Gail model has been widely used and validated with conflicting results. The current study aims to evaluate the performance of different versions of the Gail model by means of systematic review and meta-analysis with trial sequential analysis (TSA).

Methods: Three systematic review and meta-analyses were conducted. Pooled expected-to-observed (E/O) ratio and pooled area under the curve (AUC) were calculated using the DerSimonian and Laird random-effects model. Pooled sensitivity, specificity and diagnostic odds ratio were evaluated by bivariate mixed-effects model. TSA was also conducted to determine whether the evidence was sufficient and conclusive.
\end{abstract}

Results: Gail model 1 accurately predicted breast cancer risk in American women (pooled E/O = 1.03; 95\% $\mathrm{Cl} 0$. 76-1.40). The pooled E/O ratios of Caucasian-American Gail model 2 in American, European and Asian women were 0.98 (95\% Cl 0.91-1.06), 1.07 (95\% Cl 0.66-1.74) and 2.29 (95\% Cl 1.95-2.68), respectively. Additionally, Asian-American Gail model 2 overestimated the risk for Asian women about two times (pooled E/O = 1.82; 95\% Cl 1. 31-2.51). TSA showed that evidence in Asian women was sufficient; nonetheless, the results in American and European women need further verification.

The pooled AUCs for Gail model 1 in American and European women and Asian females were 0.55 (95\% Cl 0.53-0.56) and 0.75 (95\% Cl 0.63-0.88), respectively, and the pooled AUCs of Caucasian-American Gail model 2 for American, Asian and European females were 0.61 (95\% Cl 0.59-0.63), 0.55 (95\% Cl 0.52-0.58) and 0.58 (95\% Cl 0.55-0.62), respectively. The pooled sensitivity, specificity and diagnostic odds ratio of Gail model 1 were 0.63 (95\% Cl 0.27-0.89), 0.91 (95\% Cl 0. 87-0.94) and 17.38 (95\% Cl 2.66-113.70), respectively, and the corresponding indexes of Gail model 2 were 0.35 (95\% Cl $0.17-0.59), 0.86$ (95\% Cl 0.76-0.92) and 3.38 (95\% Cl 1.40-8.17), respectively.

Conclusions: The Gail model was more accurate in predicting the incidence of breast cancer in American and European females, while far less useful for individual-level risk prediction. Moreover, the Gail model may overestimate the risk in Asian women and the results were further validated by TSA, which is an addition to the three previous systematic review and meta-analyses.

Trial registration: PROSPERO CRD42016047215.

Keywords: Breast cancer, Gail model, Systematic review, Meta-analysis, Trial sequential analysis

\footnotetext{
* Correspondence: songfengju@163.com; chenkexin@tjmuch.com

Department of Epidemiology and Biostatistics, Key Laboratory of Cancer

Prevention and Therapy, Tianjin Key Laboratory of Breast Cancer Prevention

and Therapy, Ministry of Education, National Clinical Research Center for

Cancer, Tianjin Medical University Cancer Institute and Hospital, Huanhu Xi

Road, Tiyuan Bei, Hexi District, Tianjin 300060, People's Republic of China
} 


\section{Background}

Breast cancer is the most common cancer in women with high morbidity and mortality rates [1]. Risk assessment tools estimating the individual's absolute risk for developing breast cancer and identifying the women at high level of risk are crucial for decision-making about prevention and screening.

The Breast Cancer Risk Assessment Tool (BCRAT) [2], also known as the Gail model, was the most widely used appraisal tool for predicting the absolute risk of developing breast cancer. Individuals with 5-year risk exceeding $1.67 \%$ were considered high risk [3]. In 1992, the tool was modified to specifically predict invasive breast cancer, and this updated model, referred to as Gail model 2 (Caucasian-American Gail model) [4], has been used for determining the eligibility of subjects for chemoprevention of invasive breast cancer [5, 6]. In addition, this modified Gail model was also updated subsequently to predict the risk for other ethnic populations, such as African-American [7] and Asian-American [8] females.

A number of studies have been conducted to validate the Gail model in American [9-27], European [28-37], Asian [38-50] and Oceanian [51, 52] women. However, these studies showed variability in their calibration (expected-to-observed (E/O) ratio) and discrimination (Concordance-statistic (C-statistic) or area under the curve (AUC)). Although three systematic review and metaanalyses validated the Gail model previously [53-55], 19 studies [13, 14, 17-20, 22-24, 32-36, 38, 40, 41, 51, 52] with inconsistent results have been published subsequently or were not included in the previous meta-analyses. However, the evaluation studies launched in China [39, 42-50] have not been incorporated before and the diagnostic accuracy of the Gail model has not been fully evaluated.

There is increasing awareness that a meta-analysis also needs sufficient sample size to get a stable conclusion. Trial sequential analysis (TSA) was introduced to calculate the required information size (RIS) for metaanalysis and to decide whether the evidence was sufficient and conclusive $[56,57]$.

Here, we conducted a systematic review and metaanalysis to comprehensively evaluate the performance of different versions of the Gail model from three different dimensions (calibration, discrimination and diagnostic accuracy). In addition, the meta-analysis for calibration of the Gail model was also challenged by TSA.

\section{Methods}

\section{Study registration}

The current systematic review and meta-analysis was performed according to MOOSE guidelines [58] and has been registered with the International Prospective Register of Systematic Reviews (PROSPERO; registration number CRD42016047215).

\section{Literature search strategy}

Two investigators conducted a literature search in the PubMed, Embase, WANFANG [59], VIP [60] and China National Knowledge Infrastructure (CNKI) [61] databases for all articles concerning the performance of the Gail model in females.

We used "mammary OR breast cancer OR carcinoma OR tumor OR neoplasm" AND "calibration OR validate OR validation OR screen OR screening OR expected-toobserved ratio OR E/O ratio" AND "Gail model OR breast cancer risk assessment tool OR BCRAT" as medical subject headings (MeSH) in searching for studies evaluating the calibration of the Gail model.

The terms "mammary OR breast cancer OR carcinoma OR tumor OR neoplasm" AND "discrimination OR validate $\mathrm{OR}$ validation $\mathrm{OR}$ screen $\mathrm{OR}$ screening $\mathrm{OR}$ sensitivity OR specificity OR area under the curve OR AUC OR C-statistic" AND "Gail model OR breast cancer risk assessment tool OR BCRAT" were used for retrieving publications assessing the discrimination and diagnostic accuracy of the Gail model.

Publications in English and Chinese language between 1 January 1989 (when the Gail model was developed [3]) and 31 July 2016 were included. Listed references were also manually checked for relevant papers.

\section{Inclusion and exclusion criteria}

The inclusion and exclusion criteria for this metaanalysis included the following: studies validating the performance of the original (Gail model 1) or modified (Gail model 2) Gail model in women [3, 4]; calibration of the Gail model was prospectively estimated focusing on cohort studies that provided the $\mathrm{E} / \mathrm{O}$ ratio and its 95\% confidence interval (CI) or offered sufficient data for calculating the expected and observed number of breast cancer; discrimination of the Gail model was estimated focusing on the studies providing the C-statistic or AUC and its 95\% CI for the Gail model; the diagnostic meta-analysis included publications that provided sufficient data for calculating the true positive (TP), false positive (FP), false negative (FN) and true negative (TN) values of the Gail model, respectively; the threshold of the Gail model was limited to $\geq 1.67 \%$; the sample size should be higher than 100 and the mean follow-up period for the cohort studies should be longer than 1 year; and when multiple publications included the same population, studies with larger sample size or longer follow-up period were incorporated and studies with independent validations in subsequent articles were included. 
Literature selection for the systematic review and metaanalysis

For the calibration of the Gail model, 435 studies were found in the electronic databases and 10 were manually retrieved. After careful examination, 419 publications were excluded: 62 were duplicated records, 235 were not related, 70 were reviews and 52 were conference abstracts. In addition, two studies were excluded [27, 62] as they focused on the same population but with smaller sample size than other studies [17, 31]. In the end, 24 studies with 29 datasets were included.

After excluding the duplicated records, 356 studies were retrieved for estimating the discrimination of the Gail model. Of these, 311 were excluded in the preliminary screening and 19 were further eliminated by full-text reading. Moreover, seven studies [31, 62-67] were also excluded as they focused on the same population but with a shorter study period or smaller sample size than other included studies [17, 27, 51]. In total, 26 studies incorporating 29 datasets were included in this meta-analysis.

For the diagnostic accuracy of the Gail model, 455 publications were retrieved at the beginning. After preliminary screening and the full-text reading, 13 studies were finally included (Fig. 1).

Studies included in the aforementioned three metaanalyses overlapped to some extent, as some of them provided both the E/O ratio and AUC or the diagnostic accuracy of the Gail model $[11,15,17,18,20$, $30-33,35,39,41,44,45]$.

\section{Data abstraction}

Two investigators independently extracted data. Relevant information included the first author, publication year, geographic region, versions of the Gail model (Gail model 1 or Gail model 2 for Caucasian-American, Asian-American and African-American women), risk prediction period, study design, study population, sample size, mean age of participants as well as the risk for breast cancer, study period, follow-up period, E/O ratio with 95\% CI, C-statistic or AUC with $95 \% \mathrm{CI}$ and number of true positive (TP), false positive (FP), false negative (FN) and true negative (TN) values. The quality of the included studies was assessed by Newcastle-Ottawa Scale (NOS) [68] and the studies incorporated in the diagnostic meta-analysis were assessed by Quality Assessment Diagnostic Accuracy Studies (QUADAS) [69]. Any discrepancies were resolved by consensus, and where needed the corresponding author was contacted.

\section{Statistical analyses}

Calibration assessed how closely the number of subjects predicted to develop breast cancer matched the observed number of breast cancer cases diagnosed during a specific period. This was calculated by E/O ratio and the $95 \% \mathrm{CI}$ of the $\mathrm{E} / \mathrm{O}$ ratio was computed as: $\mathrm{E} / \mathrm{O}$ ratio $\times$ exp. $( \pm 1.96 \times 1 / \sqrt{ }(\mathrm{O}))$ [11]. A well-fitting calibration should be close to 1.0. The discrimination value was assessed by C-statistic, which measures the Gail model's ability to discriminate the women who will and will not develop breast cancer; moreover, it was considered

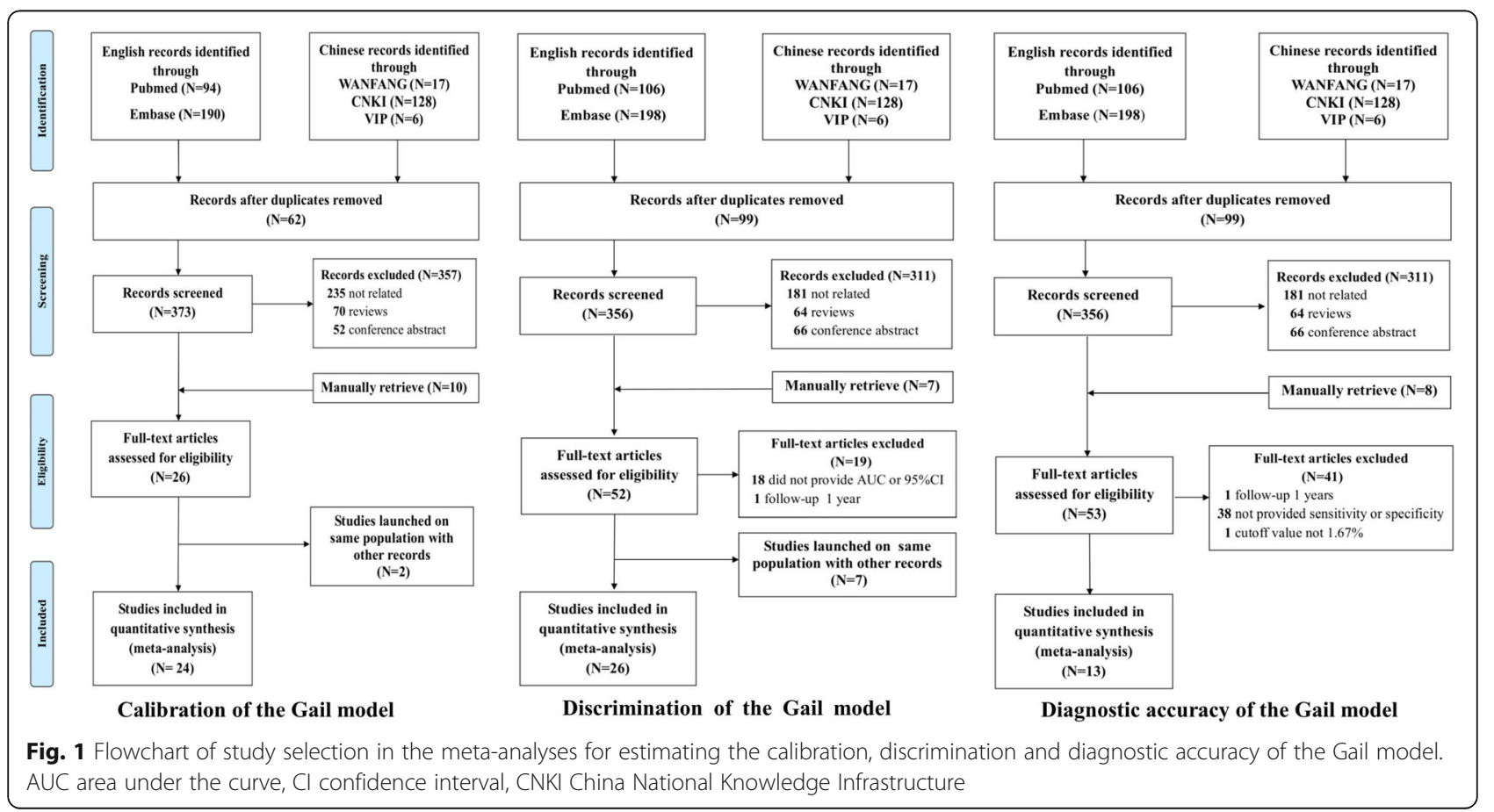


identical to the AUC in the current study [54]. A C-statistic/AUC of 0.5 was considered as no discrimination, whereas 1.0 indicates perfect discrimination.

The pooled E/O ratio and C-statistic/AUC of the Gail model were calculated using DerSimonian and Laird's random-effects model [70]. The $I^{2}$ value was employed to evaluate the heterogeneity among the studies, and subgroup analyses were carried out to identify the source of the heterogeneity. Sensitivity analysis was conducted to assess the influence of each study on the combined effects by sequentially omitting each dataset [71]. Cumulative meta-analyses were launched to investigate the trend of the pooled $\mathrm{E} / \mathrm{O}$ ratio and $\mathrm{C}$-statistic/ AUC ranked by the publication year and sample size [72]. Visualized asymmetry of the funnel plot and Egger's regression test were assessed to detect publication bias. Pooled effects were also adjusted by the Duval and Tweedie trim-and-fill method [73-75].

The pooled estimations of sensitivity, specificity and diagnostic odds ratio (DOR) were calculated using a bivariate mixed-effects model. The DOR is the ratio of risk odds in breast cancer cases relative to that in controls [76]. Publication bias was detected by Deeks' funnel plot, using $1 /$ root (effective sample size) vs $\log$ DOR. $P<0.05$ for the slope coefficient indicates significant asymmetry [77].

In the current study, TSA was conducted to determine whether the sample size incorporated in the metaanalysis was sufficient for evaluating the calibration of the Gail model. The included cohort studies are identified as trials for calculating the difference in breast cancer incidence between the expected and observed groups, and accordingly the total sample size is doubled. For the TSA, when the Z-curve crosses the conventional boundary, a significant difference is considered to exist between the expected group and the observed group for breast cancer incidence. Moreover, if the $Z$-curve passes through the trial sequential monitoring boundary or required information size (RIS) boundary, the evidence is considered sufficient and conclusive. Otherwise, the evidence is adjudged inconclusive and more studies were required to further verify the results $[56,57]$. Furthermore, in order to evaluate the effect of the Chinese studies on the performance of the Gail model, a sensitivity analysis was conducted by eliminating the studies retrieved from the WANFANG, VIP and CNKI databases.

Pooled E/O ratio and AUC were synthesized using Comprehensive Meta Analysis version 2.0 (Biostat, Englewood, NJ, USA). Pooled sensitivity, specificity and DOR were conducted with Stata statistical software version 14.0 (StataCorp, College Station, TX, USA). The trial sequential analyses program (version 0.9 beta) was used for the TSA [78] (Copenhagen Trial Unit, Centre for Clinical Intervention Research, Copenhagen, Denmark, 2011).

\section{Results}

\section{Calibration of the Gail model}

Twenty-four studies incorporating 29 records were included to evaluate the calibration of the Gail model [9-20, 28-35, 38, 39, 41, 52] (Table 1). The pooled E/O ratio was 1.16 (95\% CI 1.05-1.30) with a high level of heterogeneity between studies $\left(I^{2}=98.8 \% ; p<0.01\right)$ (Fig. 2a). Sensitivity analysis showed that the combined E/O ratio and 95\% CI were not significantly altered before and after the omission of each dataset (see Additional file 1A). Cumulative analysis showed that by continually increasing the publication year and the sample size, the $95 \%$ CI became narrower and the pooled E/O ratio was closer to 1.0, which indicates that the precision of the pooled $E / O$ ratio was gradually improved (see Additional file 1B, C). Publication bias was detected by funnel plot (regression coefficient $=5.38 ; p=0.027$ ) (see Additional file 2A). According to the trim-and-fill method, the adjusted pooled E/O ratio was 1.25 (95\% CI 1.11-1.40) after trimming (see Additional file 2B).

Subgroup analysis suggested the geographic region (see Additional file 3) could partly explain the heterogeneities between these studies $(p<0.01)$. The Gail model exhibited a tendency to overpredict breast cancer risk for Asian women (pooled $\mathrm{E} / \mathrm{O}=1.98$; 95\% CI 1.58-2.48) compared to American (pooled $\mathrm{E} / \mathrm{O}=1.02 ; 95 \% \mathrm{CI}$ $0.93-1.12$ ) and European (pooled $\mathrm{E} / \mathrm{O}=1.05 ; 95 \% \mathrm{CI}$ 0.68-1.63) women (Fig. 2b-d). Publication bias did not exist in each of these subgroups (see Additional file 4).

In addition, results showed that Gail model 1 accurately predicted breast cancer risk in American women (pooled $\mathrm{E} / \mathrm{O}=1.03 ; 95 \%$ CI 0.76-1.40). However, Gail model 2 overpredicted the risk for breast cancer (pooled $\mathrm{E} / \mathrm{O}=1.20 ; 95 \%$ CI 1.07-1.35) (see Additional file 3). When further stratified by different versions of Gail model 2, the pooled E/O ratios of Caucasian-American Gail model 2 in American [11, 12, 15-20, 31], European $[28-30,32-35]$ and Asian $[39,41]$ women were 0.98 (95\% CI 0.91-1.06), 1.07 (95\% CI 0.66-1.74) and 2.29 (95\% CI 1.95-2.68), respectively. The pooled E/O ratio for Asian women was significantly higher than that in American and European females $(p<0.001)$. Moreover, only two studies clearly stated that they used the Asian-American Gail model [38, 41], and the results indicated that it overestimated the risk for Asian women about two times (pooled $\mathrm{E} / \mathrm{O}=1.82$; $95 \% \mathrm{CI}$ 1.31-2.51) (see Additional file 5).

When excluding studies conducted in Asian women $[38,39,41]$, results showed that the Gail model precisely predicted the risk for developing breast cancer (pooled $\mathrm{E} / \mathrm{O}=1.04 ; 95 \%$ CI 0.93-1.16) (see Additional file 6A). Sensitivity analysis by singly eliminating each study showed no significant fluctuation, which indicated the 


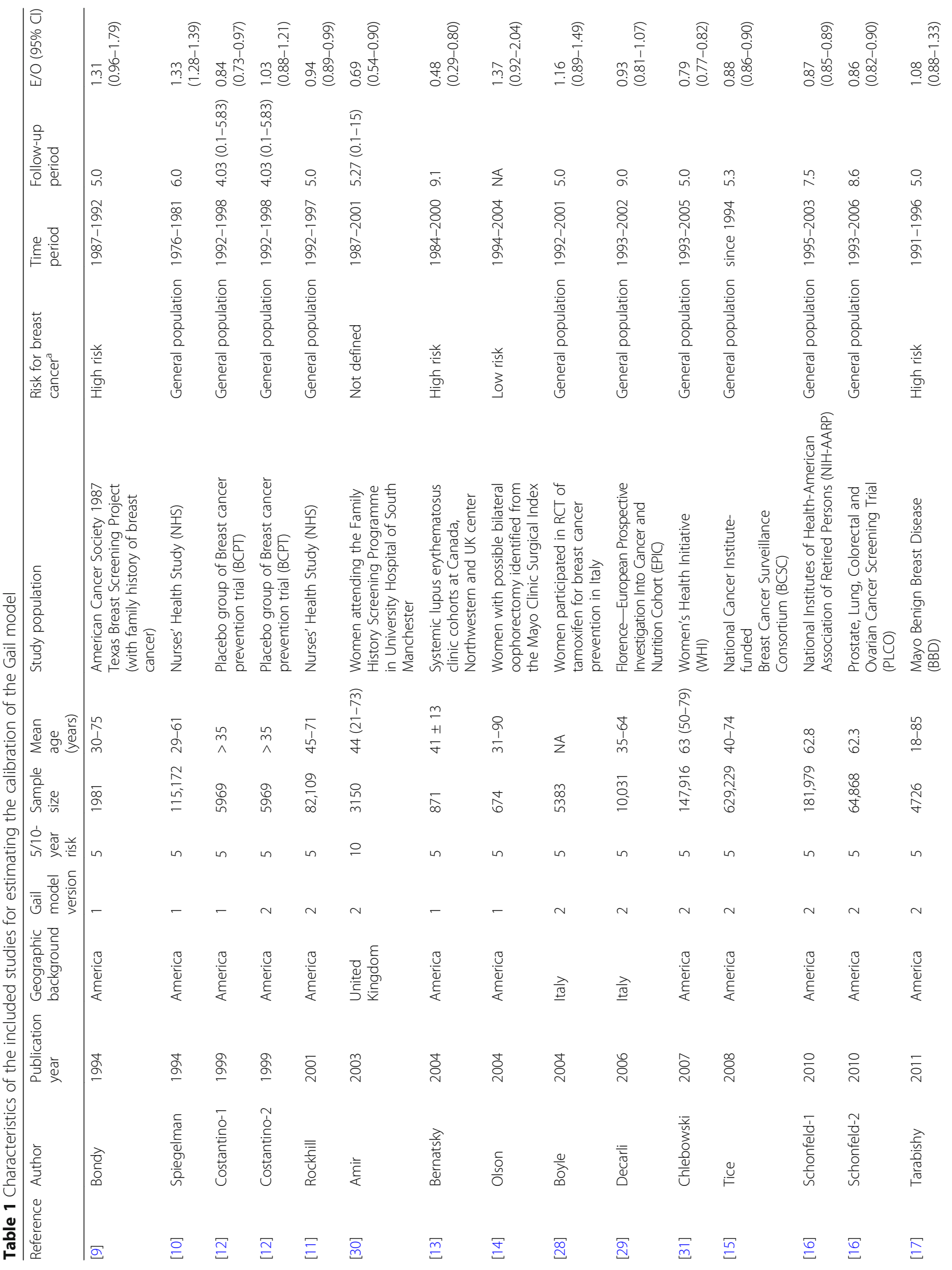




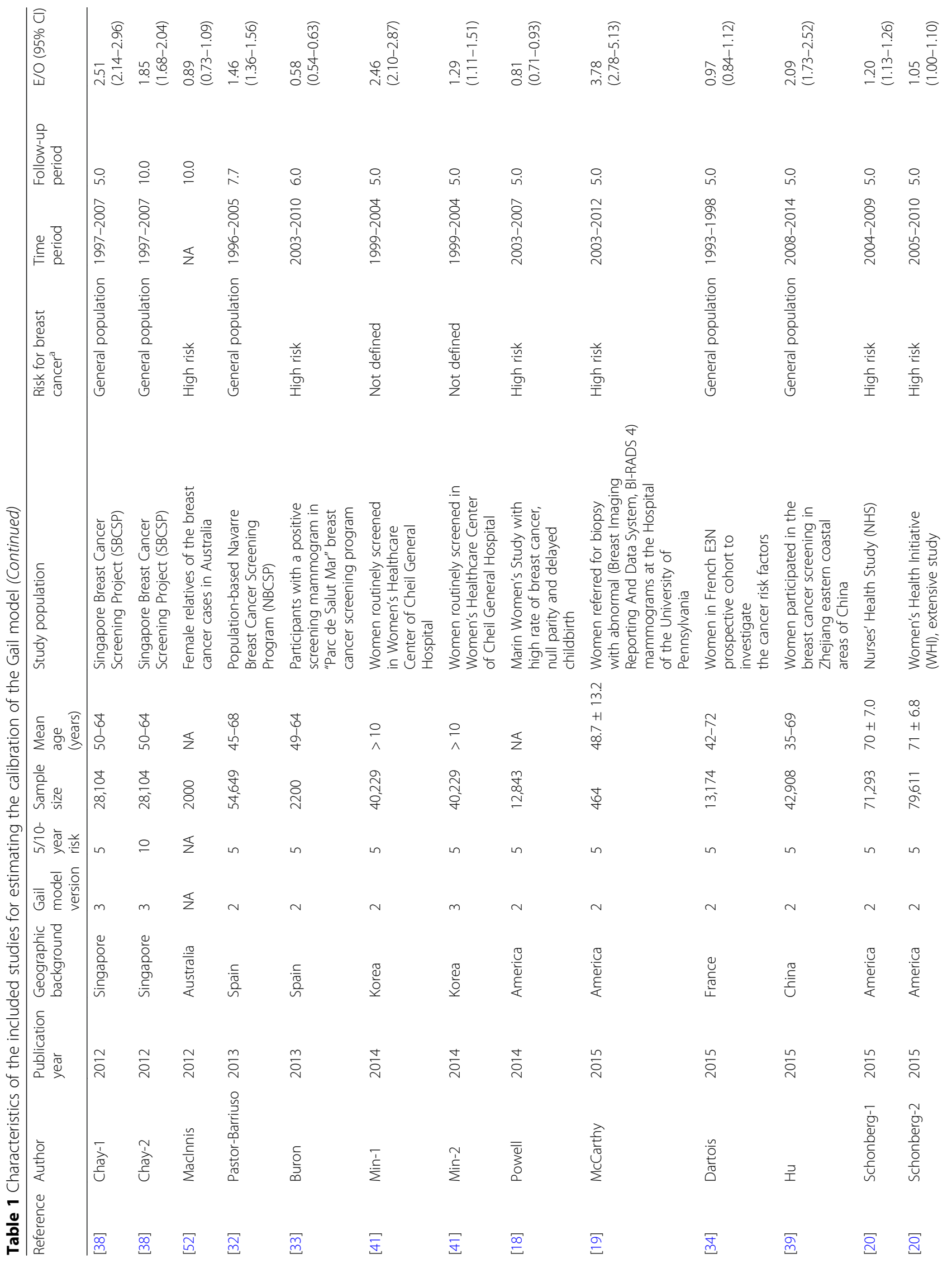




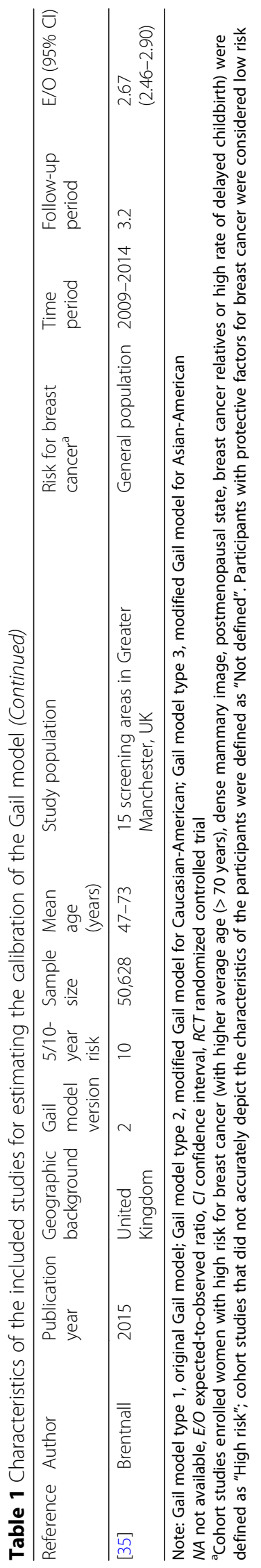




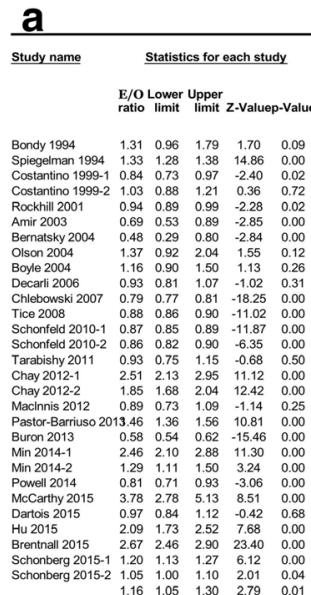

E./ ratio and $95 \% \mathrm{Cl}$
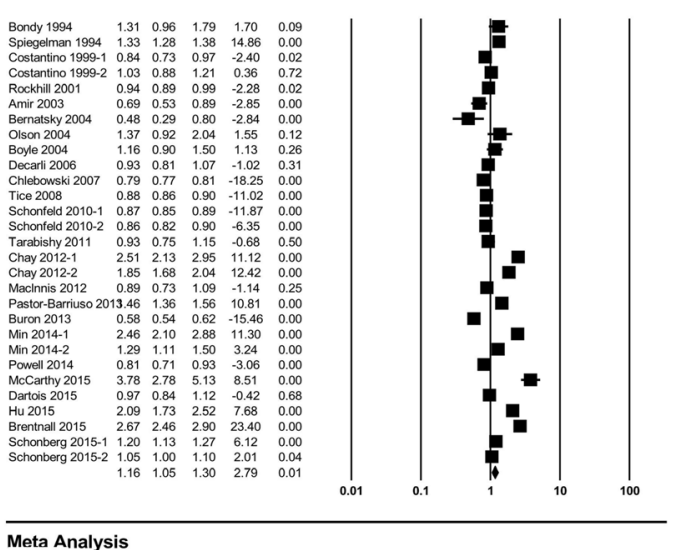

\section{Meta}

Study name

Statistics for each study E/O Lower Upper
ratio limit limit Z-Valuep-Value

$\begin{array}{llllll}\text { Bondy } 1994 & 1.31 & 0.96 & 1.79 & 1.70 & 0.09\end{array}$

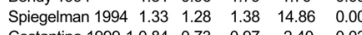
\begin{tabular}{lllll} 
Costantino 1999-1 0.84 & 0.73 & 0.97 & -2.40 & 0.02 \\
\hline
\end{tabular}

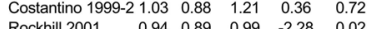
\begin{tabular}{llllll} 
Rockhill 2001 & 0.94 & 0.89 & 0.99 & -2.28 & 0.02 \\
\hline
\end{tabular} \begin{tabular}{lllllll} 
Bernatsky 2004 & 0.48 & 0.29 & 0.80 & -2.84 & 0.00 \\
\hline & 1.37 & 0.92 & 2.04 & 1.55 & 0.12
\end{tabular} $\begin{array}{llllll}\text { Clson 2wut } & 1.37 & 0.92 & 2.04 & -2.55 & 0.12\end{array}$

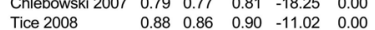
$\begin{array}{llllll}\text { Schonfeld 2010-1 } & 0.87 & 0.85 & 0.89 & -11.87 & 0.00\end{array}$ Schonfeld 2010-2 $0.86 \quad 0.82 \quad 0.90 \quad-6.35 \quad 0.00$ $\begin{array}{llllll}\text { Tarabishy } 2011 & 0.93 & 0.75 & 1.15 & -0.68 & 0.50\end{array}$ $\begin{array}{llllll}\text { Powell } 2014 & 0.81 & 0.71 & 0.93 & -3.06 & 0.00\end{array}$ $\begin{array}{llllll}\text { McCarthy } 2015 & 3.78 & 2.78 & 5.13 & 8.51 & 0.00\end{array}$ Schonberg 2015-11.20 $1.13 \quad 1.27 \quad 6.12 \quad 0.00$ Schonberg 2015-2 1.05 $1.00 \quad 1.10 \quad 2.01 \quad 0.04$ $\begin{array}{lllll}.02 & 0.93 & 1.12 & 0.36 & 0.72\end{array}$

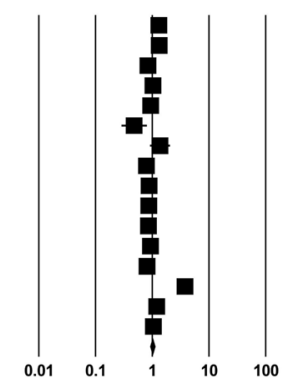

\section{Meta Analysi}

C

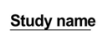

Study name

Statistics for each study E/O LowerUpper E/O Lower Upper
ratio limit limit Z-Valuep-Value

Amir 2003 Boyle 2004 $\begin{array}{lllll}0.69 & 0.53 & 0.89 & -2.85 & 0.00\end{array}$ $\begin{array}{llllll}\text { Decarli } 2006 & 0.93 & 0.81 & 1.07 & -1.02 & 0.31\end{array}$

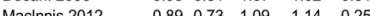
$\begin{array}{llllllll} & \text { Pastor-Barriuso } 20131.46 & 136 & 1.56 & 10.81 & 0.00\end{array}$ Buron 2013 Dartois 2015 $\begin{array}{lllll}46 & 1.36 & 1.56 & 10.81 & 0.00\end{array}$ $\begin{array}{lllll}0.58 & 0.54 & 0.62 & -15.46 & 0.00\end{array}$ $\begin{array}{llllll}0.97 & 0.84 & 1.12 & -0.42 & 0.68\end{array}$ $\begin{array}{ccccc}2.67 & 2.46 & 2.90 & 23.40 & 0.00 \\ 1.05 & 0.68 & 1.63 & 0.22 & 0.83\end{array}$

E/O ratio and $95 \% \mathrm{Cl}$

$10 \quad 100$ e

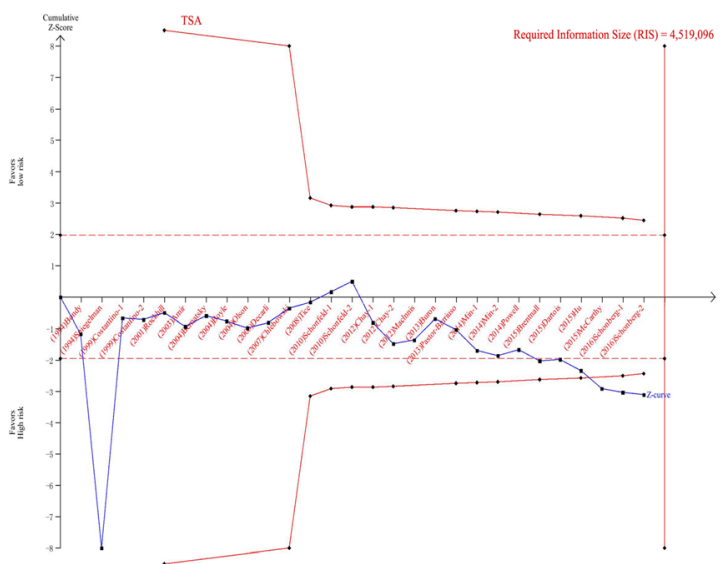

㱖

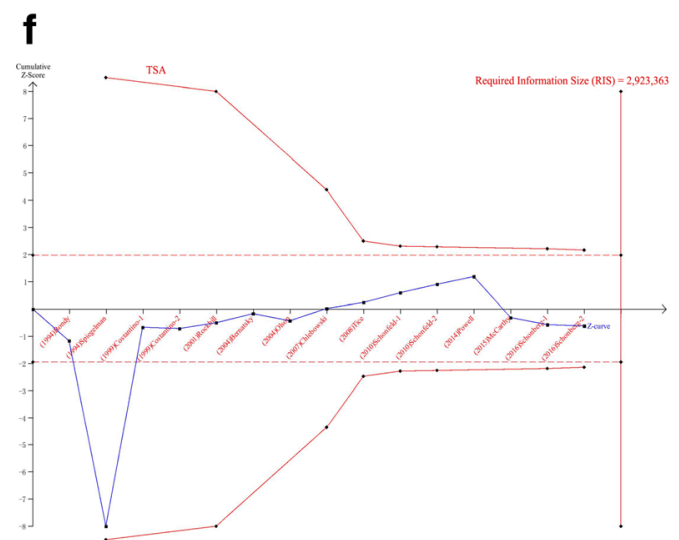

g

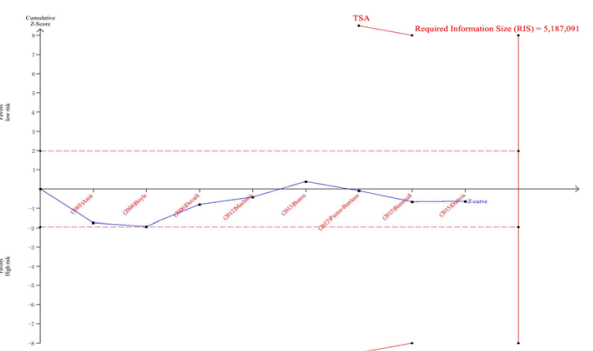

h

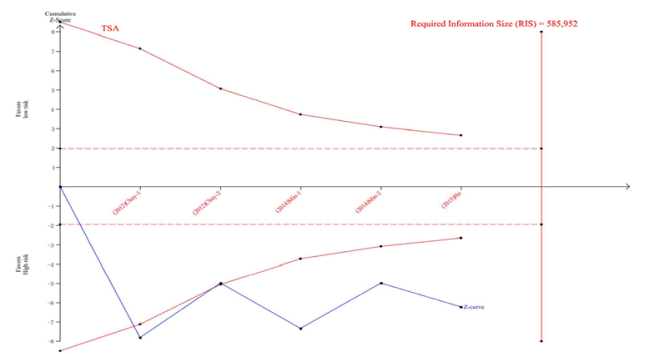

Fig. 2 Calibration of the Gail model in total and stratified by geographic region with the trial sequential analysis. Forest plot of the pooled E/O ratio for the Gail model in total (a) and studies from America (b), Europe (c) and Asia (d), respectively. Trial sequential analysis (TSA) for pooled E/ O ratio in total (e) and studies from America $(\mathbf{f})$, Europe $(\mathbf{g})$ and Asia $(\mathbf{g})$, respectively. E/O expected-to-observed ratio, Cl confidence interval 
stability of the results (see Additional file 6B). Cumulative analysis showed that the pooled $\mathrm{E} / \mathrm{O}$ ratio became progressively closer to 1.0 according to accumulation of the publication year and sample size (see Additional file 6C, D). When stratified by different versions of the Gail model, the combined E/O ratios of Gail model 1 and CaucasianAmerican Gail model 2 were reported to be 1.03 (95\% CI $0.76-1.40)$ and 1.05 (95\% CI 0.93-1.17), respectively, with no significant difference $(p=0.93)$ (see Additional file 7). Stratified analysis showed that the studies with high reporting quality were prone to have a precise estimate of breast cancer risk (pooled $\mathrm{E} / \mathrm{O}=0.88$; $95 \% \mathrm{CI} 0.71-1.10$ vs pooled $\mathrm{E} / \mathrm{O}=1.13 ; 95 \%$ CI $1.00-1.29 ; p=0.06)$. However, no difference was found when stratified by the geographic region and other factors (see Additional file 8).

\section{Trial sequential analysis}

In the TSA, the cumulative $Z$-curve passed through both the conventional and the trial sequential monitoring boundary, which suggested the evidence was sufficient to verify the overprediction of the Gail model (Fig. 2e). When stratified by geographic region, the cumulative $Z$ curve did not cross the conventional and RIS boundary in American (Fig. 2f) and European (Fig. 2g) studies, demonstrating the accurate prediction of the Gail model. However, the evidence was insufficient to draw a firm conclusion and more related studies were required to confirm the results. With respect to Asian women, the $Z$-score crossed both the conventional and TSAadjusted boundary, which showed the overestimation of breast cancer risk in Asian females and the evidence was sufficient and conclusive (Fig. 2h).

\section{Discrimination of the Gail model}

Twenty-six articles with 29 datasets describing the C-statistic/AUC of the Gail model were combined to evaluate its pooled discrimination [11, 15, 18-24, 27, 29-32, 34-36, 39-46, 51] (Table 2). The pooled AUC was 0.60 (95\% CI 0.58-0.62) with substantial heterogeneity $\left(I^{2}=97.0 \% ; p<0.01\right)$ (Fig. 3a). Sensitivity analysis suggested that the results were stable, and cumulative analysis indicated that the 95\% CI became narrower and the pooled AUC progressively rose toward 0.60 with the accumulation of data ranked by publication year and sample size (see Additional file 9A-C).

When stratified by geographic region, the pooled AUCs in American, European and Asian women were 0.60 (95\% CI $0.58-0.62), 0.58$ (95\% CI $0.55-0.60)$ and 0.61 (95\% CI 0.52-0.69), respectively, with no significant heterogeneities $(p=0.30)$ (Fig. 3b-d and see Additional file 10). Subgroup analysis also showed that the pooled AUC in studies with sample size $\geq 10,000$ was lower (0.57 vs $0.64 ; p=0.01)$. However, the combined AUC was not markedly changed when stratified by other factors (see Additional file 10). The funnel plot indicated no publication bias (Egger's regression coefficient = $-1.25 ; p=0.54$ ) (see Additional file 11A). According to the trim-and-fill method, eight studies had to be trimmed and the adjusted pooled AUC was 0.63 (95\% CI 0.60-0.65) after trimming (see Additional file 11B). In addition, when stratified by geographic region, the funnel plot found significant publication bias across the studies in Europe (Egger's regression coefficient $=4.45$; $p=0.01$ ) (see Additional file 12). After trimming, the adjusted AUC in European women was 0.59 (95\% CI 0.56-0.62).

Results also showed the pooled AUC for Gail model 1 was 0.70 (95\% CI 0.57-0.77), and when stratified by the geographic region the pooled AUCs for Gail model 1 in American and European women [22, 36] and Asian females [42, 44, 46] were 0.55 (95\% CI $0.53-0.56)$ and 0.75 (95\% CI 0.63-0.88), respectively (see Additional files 10 and 13). Additionally, the pooled AUC for Gail model 2 was 0.59 (95\% CI $0.57-0.61$ ), and when stratified by the geographic region and different versions of Gail model 2 the pooled AUCs for Caucasian-American Gail model 2 in American [15, 17-21, 23, 24, 27], Asian [39, 41, 43, 45] and European [29, 30, 32, 34, 35, 51] females were 0.61 (95\% CI $0.59-0.63), 0.55$ (95\% CI $0.52-0.58$ ) and 0.58 (95\% CI $0.55-0.62$ ), respectively (see Additional file 13). However, only one study clearly stated that they used Asian-American Gail model 2, and the AUC was reported to be 0.54 (95\% CI 0.50-0.59) [41].

\section{Diagnostic accuracy of the Gail model}

Thirteen studies [11, 15, 25, 26, 31, 33, 37, 44, 45, 47-50] with 783,601 participants were included in this diagnostic meta-analysis (Table 3). The combined sensitivity, specificity and pooled DOR were 0.43 (95\% CI $0.24-0.64), 0.88$ (95\% CI 0.81-0.92), and 5.44 (95\% CI 2.17-13.63), respectively (Fig. 3e). Deeks' funnel plot suggested that publication bias existed among the studies $(p=0.026)$ (see Additional file 14A).

When stratified by geographic region, the pooled sensitivity, specificity and DOR in American and European women were 0.26 (95\% CI 0.15-0.42), 0.84 (95\% CI $0.72-$ 0.91 ) and 1.79 (95\% CI 1.57-2.05), respectively (Fig. 3f) and Deeks' funnel plot showed no publication bias $(p=0.50)$ (see Additional file 14B). With respect to Asian women, the pooled sensitivity, specificity and DOR were 0.63 (95\% CI 0.30-0.87), 0.91 (95\% CI 0.84-0.95) and 17.56 (95\% CI 4.13-74.59), respectively (Fig. 3g). However, publication bias persisted ( $p=0.019$ ) (see Additional file 14C).

When further stratified by different versions of the Gail model, the pooled sensitivity, specificity and DOR of Gail model 1 were 0.63 (95\% CI 0.27-0.89), 0.91 (95\% CI $0.87-0.94$ ) and 17.38 (95\% CI 2.66-113.70), respectively, and the corresponding indexes of Gail model 2 


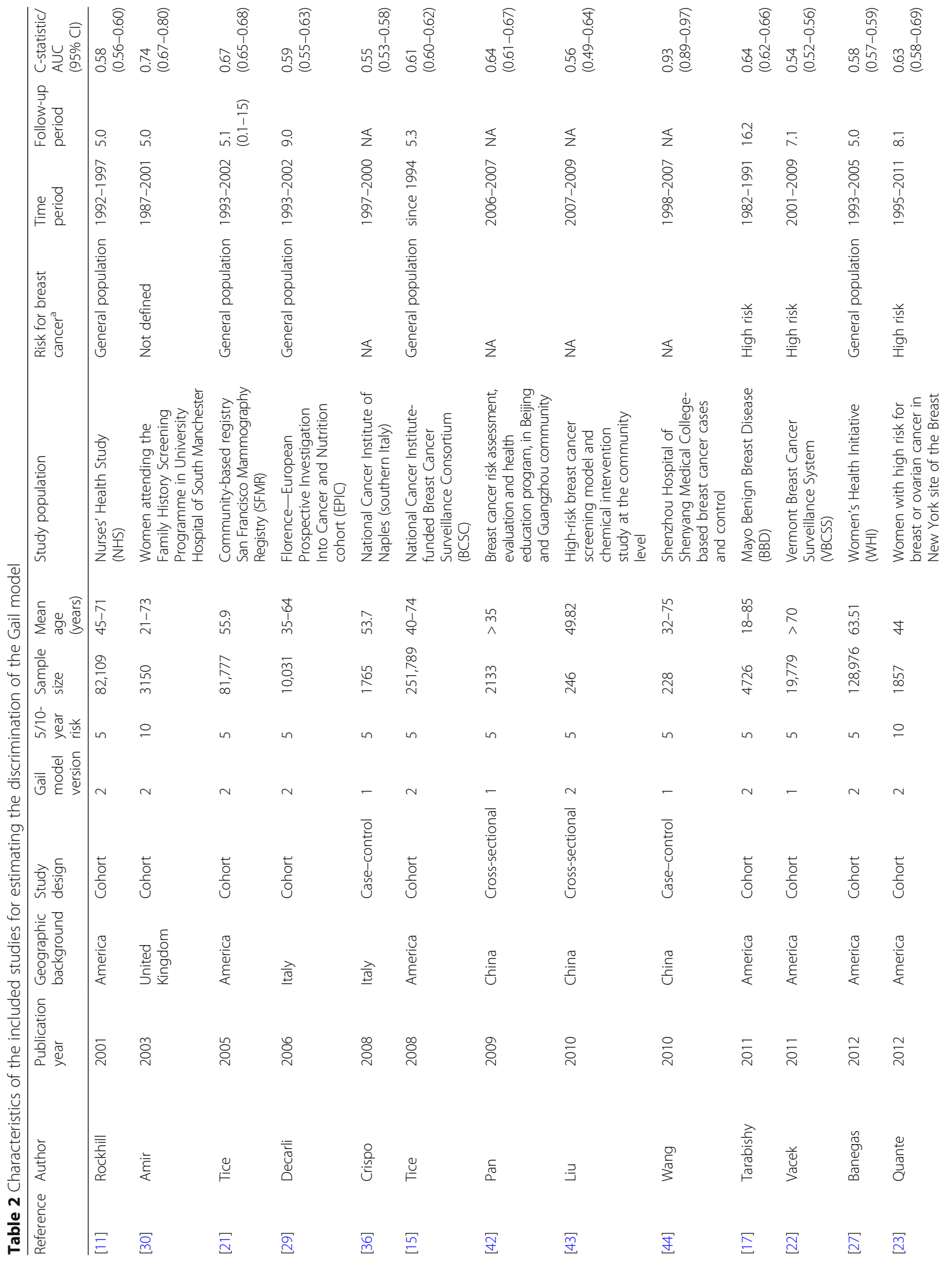




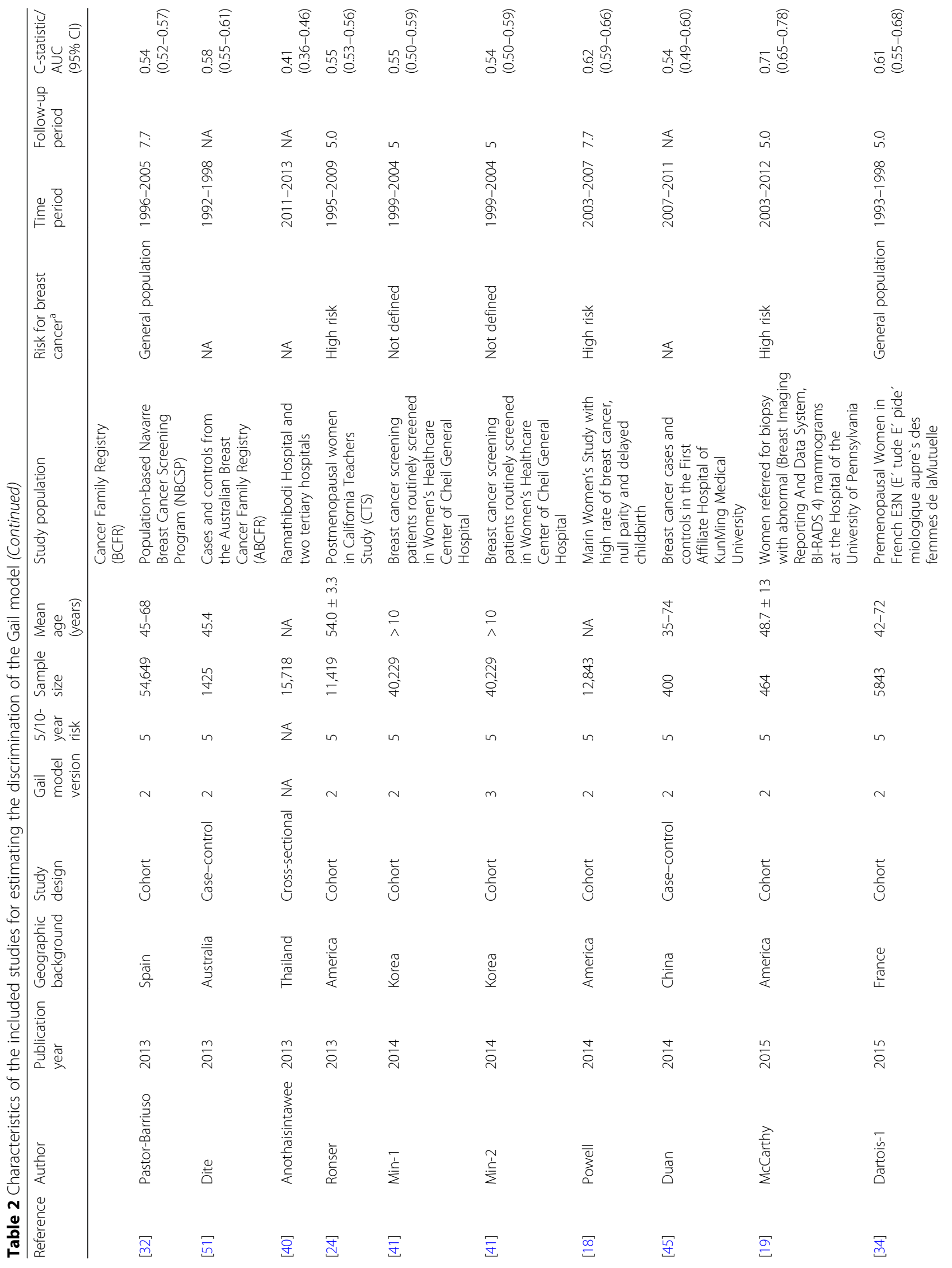




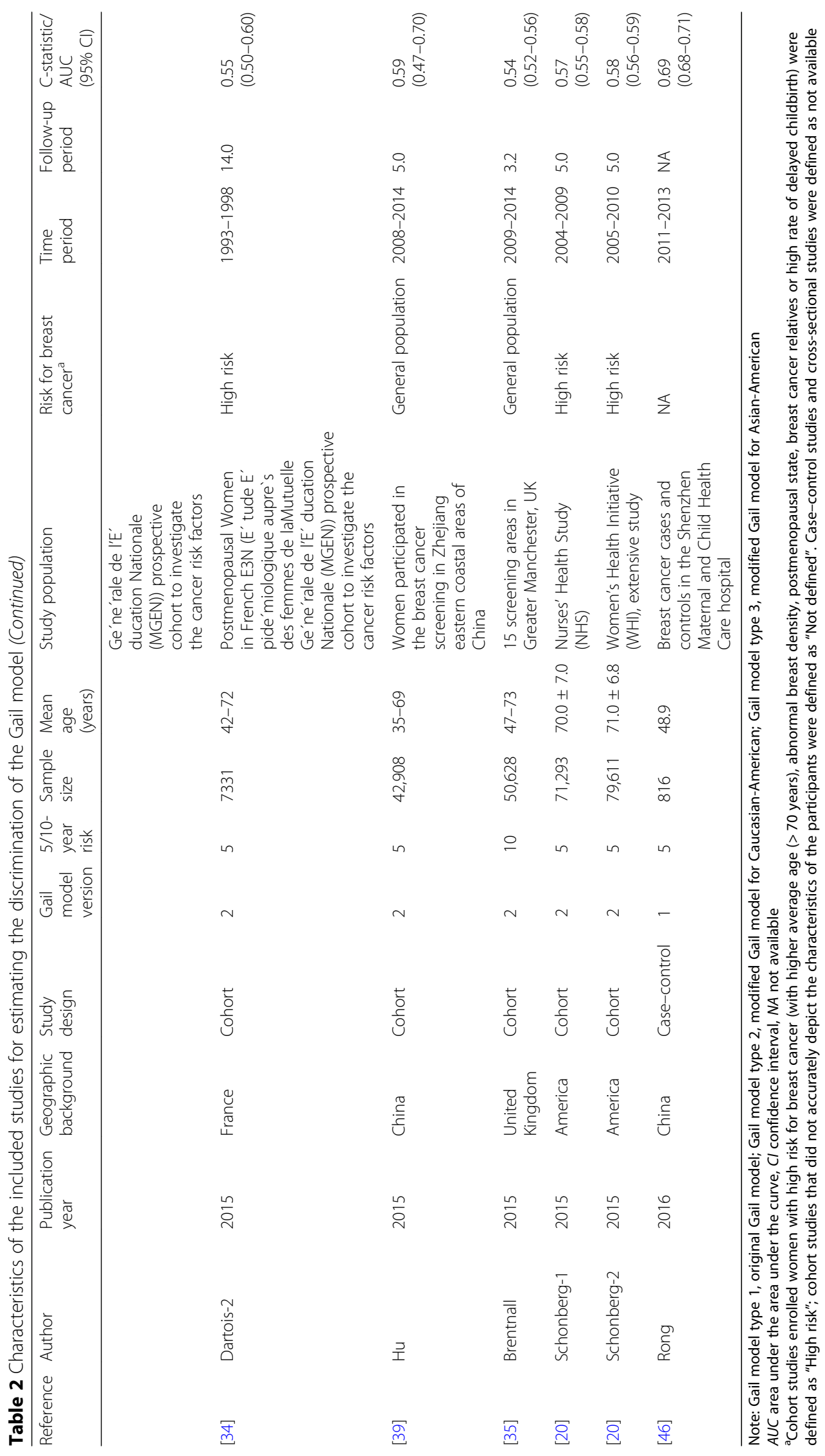


a

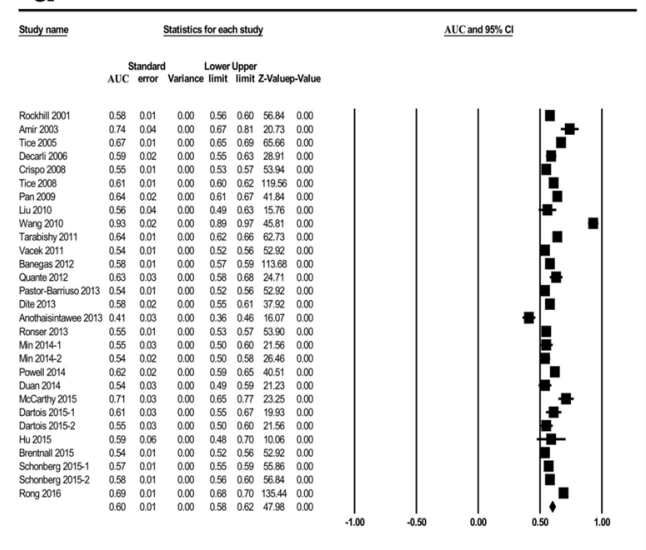

Meta Analysis

b
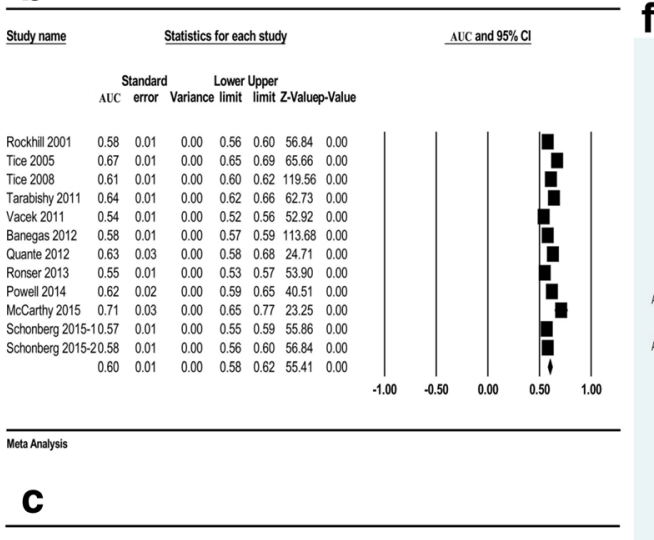

Study name Standard Lower Upper
AUC error Variance limit limit Z-Valuep-Value

$\begin{array}{llllllll}\text { Amir } 2003 & 0.74 & 0.04 & 0.00 & 0.67 & 0.81 & 20.73 & 0.00\end{array}$ $\begin{array}{llllllll}\text { Decarli } 2006 & 0.59 & 0.02 & 0.00 & 0.55 & 0.63 & 28.91 & 0.00\end{array}$ $\begin{array}{llllllll}\text { Cispo } 2008 & 0.55 & 0.01 & 0.00 & 0.53 & 0.57 & 53.94 & 0.00\end{array}$ $\begin{array}{lllllll}\text { Pastor-Barriuso } 20130.54 & 0.01 & 0.00 & 0.52 & 0.56 & 52.92 & 0.00\end{array}$ $\begin{array}{lllllllll}\text { Dite } 2013 & 0.58 & 0.02 & 0.00 & 0.55 & 0.61 & 37.92 & 0.00\end{array}$

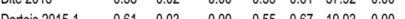

$\begin{array}{llllllll}\text { Dartois 2015-2 } & 0.55 & 0.03 & 0.00 & 0.50 & 0.60 & 21.56 & 0.00\end{array}$

$\begin{array}{llllllll}\text { Brentnall 2015 } & 0.55 & 0.03 & 0.00 & 0.50 & 0.60 & 21.56 & 0.00 \\ & 0.01 & 0.00 & 0.52 & 0.56 & 52.92 & 0.00\end{array}$ $\begin{array}{lllllll}0.54 & 0.01 & 0.00 & 0.52 & 0.56 & 52.92 & 0.00 \\ 0.58 & 0.01 & 0.00 & 0.55 & 0.60 & 42.73 & 0.00\end{array}$
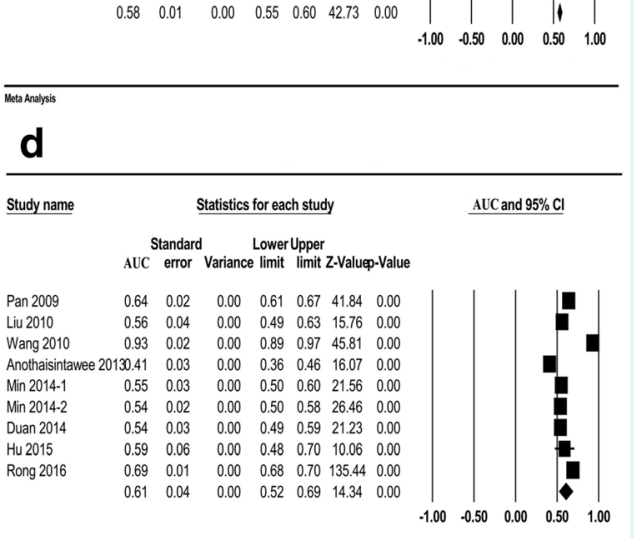

e
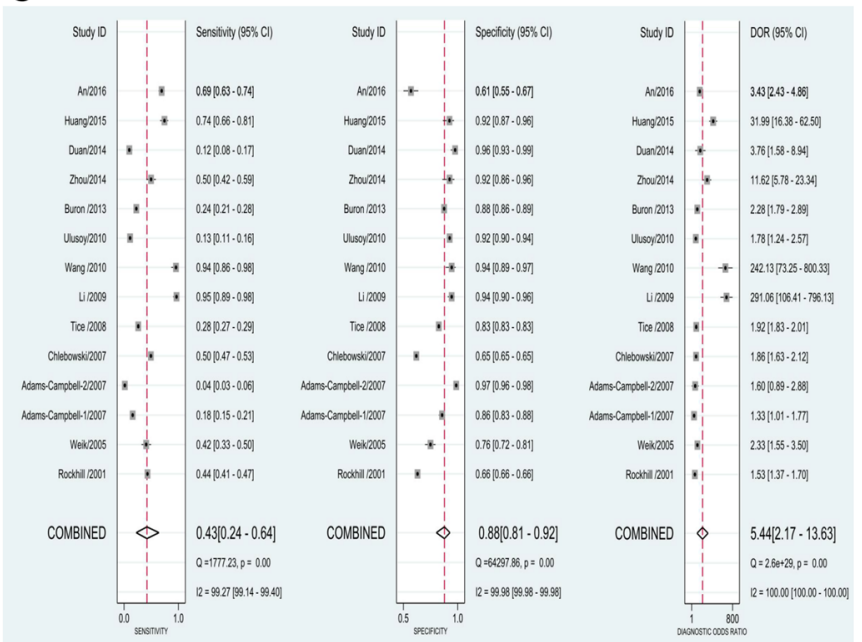

f
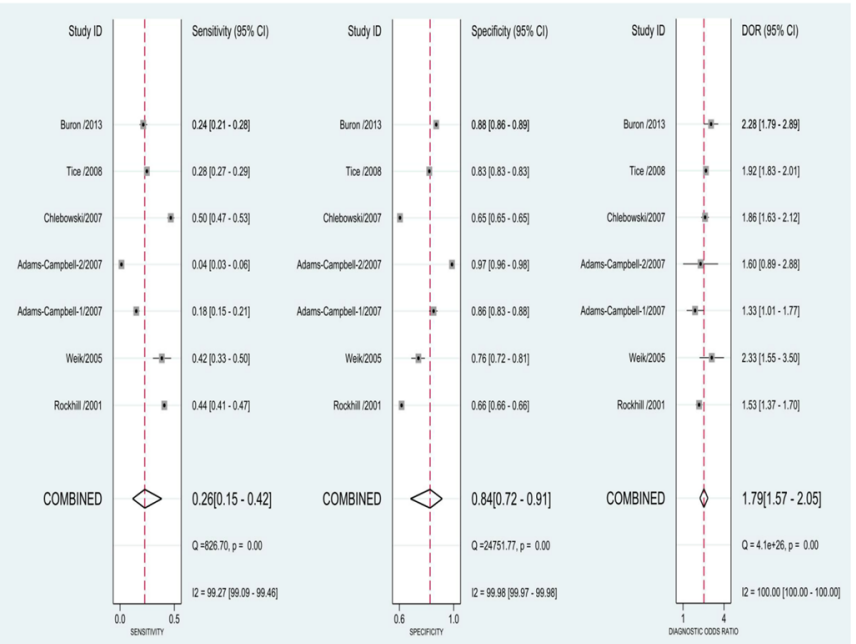

g

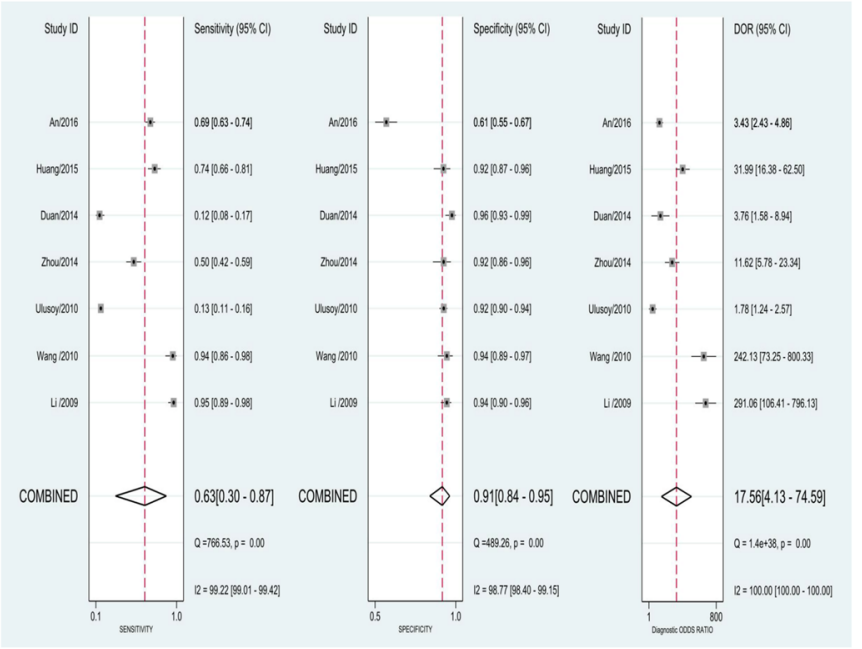

Fig. 3 (See legend on next page.) 
(See figure on previous page.)

Fig. 3 Pooled discrimination and diagnostic accuracy of the Gail model in total or stratified by geographic region. Pooled AUC/C-statistic of the Gail model in total (a) and studies from America (b), Europe (c) and Asia (d), respectively. Pooled sensitivity, specificity and diagnostic odds ratio (DOR) of the Gail model in total (e) and studies from America and Europe ( $\mathbf{f}$ ) and Asia $(\mathbf{g})$, respectively. AUC area under the curve, Cl confidence interval

were 0.35 (95\% CI 0.17-0.59), 0.86 (95\% CI 0.76-0.92) and 3.38 (95\% CI 1.40-8.17), respectively (see Additional file 15). When subgrouped by different versions of Gail model 2, the pooled sensitivity, specificity and DOR of the Caucasian-American Gail model for American and European women $[11,15,25,31,33$ ] were 0.36 (95\% CI $0.27-0.45), 0.77$ (95\% CI $0.67-0.84)$ and 1.81 (95\% CI 1.66-1.96), respectively, and for Asian females were 0.49 (95\% CI 0.11-0.88), 0.90 (95\% CI 0.76-0.96) and 8.80 (95\% CI 1.19-64.81), respectively [37, 45, 47, 50] (see Additional file 16). However, only one study stated that they used the African-American Gail model and the sensitivity and specificity were reported to be 0.04 (95\% CI 0.03-0.05) and 0.97 (95\% CI 0.96-0.98), respectively [26]. Subgroup analysis also indicated that the pooled sensitivity with sample size $<1000$ was higher than that in studies with $\geq 1000$ samples, and the pooled specificity in studies with case-control design, sample size $<1000$ and study quality $<8$ points was higher than each of their counterparts (see Additional file 17).

\section{Performance of the Gail model after excluding studies published in Chinese}

When excluding studies retrieved in the WANFANG, VIP and CNKI databases, no effect was found on the calibration of Gail model 1. The E/O ratios of the Caucasian-American Gail model and the Asian-American Gail model for Asian women were reported as 2.46 (95\% CI 2.10-2.88) and 1.82 (95\% CI 1.68-2.04), respectively (see Additional file 18A).

The pooled AUC for Gail model 1 was 0.55 (95\% CI 0.53-0.56). After excluding studies published in Chinese, only one study validated discrimination of Asian-American Gail model 2 and Caucasian-American Gail model 2 for Asian females and the AUCs were shown as 0.54 (95\% CI $0.50-0.58$ ) and 0.55 (95\% CI $0.50-0.60)$, respectively [41] (see Additional file 18B).

For the diagnostic accuracy of the Gail model, after excluding studies conducted in China, the pooled sensitivity, specificity and the DOR of the Gail model were 0.24 (95\% CI 0.14-0.38), 0.85 (95\% CI 0.75-0.92) and 1.79 (95\% CI 1.58-2.03), respectively. When stratified by different versions of the Gail model, the sensitivity, specificity and the DOR of the Caucasian-American Gail model were 0.25 (95\% CI 0.14-0.41), 0.85 (95\% CI 0.720.93 ) and 1.89 (95\% CI $1.68-2.13)$, respectively. Only one study remained to evaluate the performance of Gail model 1, and the sensitivity and specificity were reported as 0.15 (95\% CI 0.18-0.21) and 0.86 (95\% CI 0.83-0.88), respectively [26] (see Additional file 19).

\section{Discussion}

The current study comprehensively evaluated the calibration, discrimination and diagnostic accuracy of different versions of the Gail model. Gail model 1 and Caucasian-American Gail model 2 accurately predicted breast cancer risk for American and European women. However, the Caucasian-American and AsianAmerican Gail models overpredicted the risk for developing breast cancer about two times in Asian females. TSA showed that evidence in Asian women was sufficient; nonetheless, the results in American and European women need further verification. Moreover, the discrimination and the diagnostic accuracy of any versions of the Gail model were not satisfactory overall or stratified by geographic region.

The current study showed that both the CaucasianAmerican and the Asian-American Gail models overpredicted the risk for developing breast cancer in Asian women. To explain the results, firstly, the Gail model was constructed based on American white females, but the incidence of breast cancer in Asia (29.1/100,000) was much lower than that in American women (69.9/ 100,000) [1]. Accordingly, during a specific period, Asian women might not present with so many breast cancer incident cases as expected, leading to a higher $\mathrm{E} / \mathrm{O}$ ratio. Secondly, the distributions of factors included in the Gail model were different between Asian and American women. Morabia and Costanza [79] conducted an international comparison on reproductive factors in 1998 and found age at first live birth in Asian women was older than that in American females, which may present a higher risk prediction in Asia according to the Gail model [3, 12]. Another potential explanation was the lack of regular breast cancer screening in Asian women. In America, conventional mammography examination would be conducted for women aged 45-74 years every 1 or 2 years $[80,81]$ and the Gail model was constructed based on women with annual screening $[3,12]$. However, routine screening was seldom conducted in Asian women [82]; many of the breast cancer patients could not be detected and resulted in a lower number of observed breast cancer than actually existed, resulting in a higher $\mathrm{E} / \mathrm{O}$ ratio.

Gail model 1 was designed for white women who were being screened annually [3]. The current version of Gail model 2 used Surveillance Epidemiology and End Results (SEER) breast cancer rates for Asian-American women and the relative and attributable risks were derived from Asian-American females [8]. The Breast 


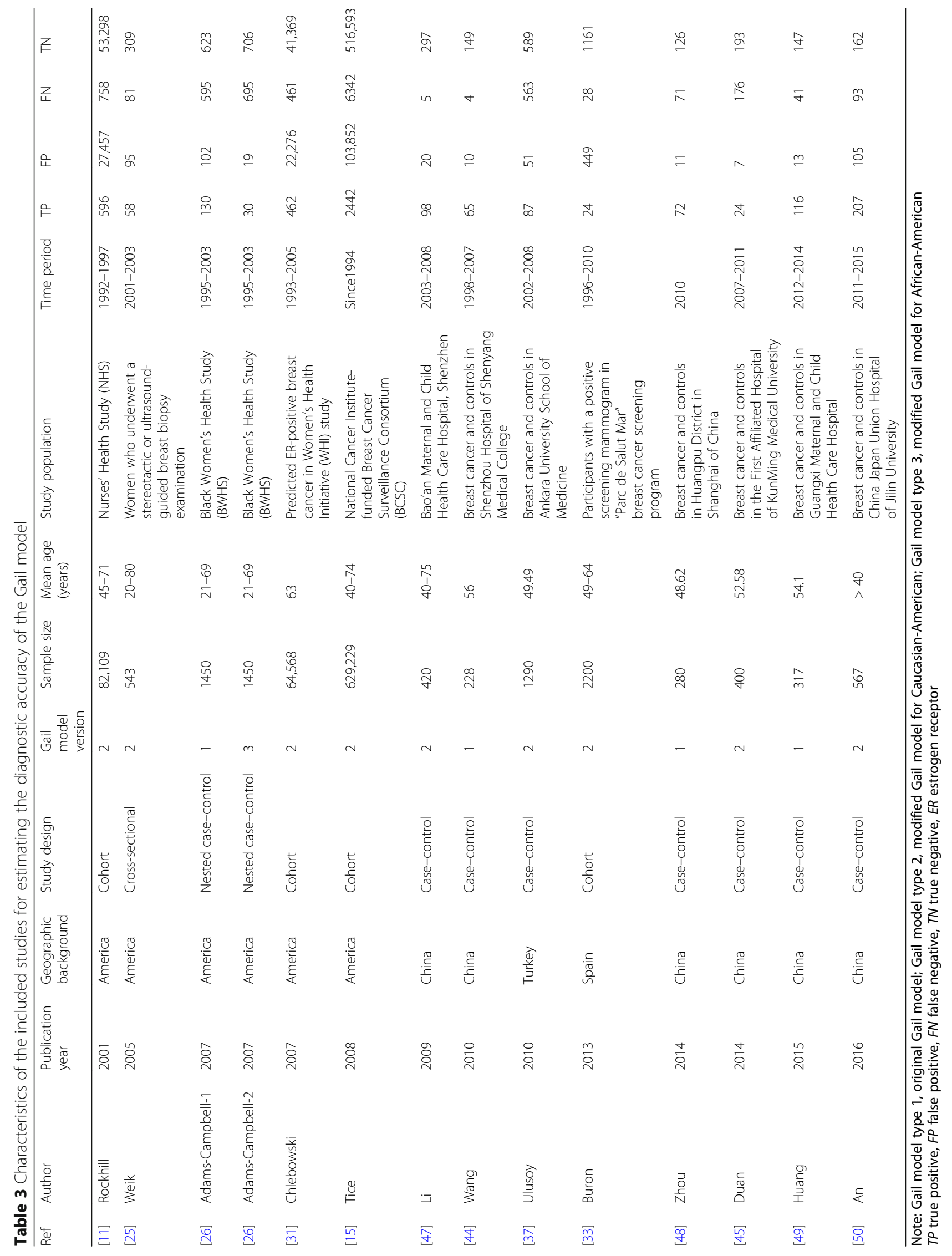


Cancer Risk Assessment Tool program specifically warns against the use of the Gail model in Asian women, where breast cancer rates are lower than those in AsianAmerican women [1]. Accordingly, the risk prediction of the Gail model should be explained with caution when applying it to Asian women and it is necessary to modify the Gail model based on the special risk factors and incidence of breast cancer in Asia, to improve its performance.

For the discrimination of the Gail model, results showed that the pooled AUC was moderately acceptable, while substantial heterogeneities exist between studies. Sample size could partly explain the phenomenon, and two studies with extreme value markedly affected the results. Anothaisintawee et al. [40] reported that the AUC of the Gail model was 0.41 with sample size > 1000, while the study conducted by Wang et al. [44] showed the AUC was 0.93 with $<1000$ participants. Subgroup analysis showed no heterogeneities in sample size $(\geq 1000$ and $<1000)$ when these two datasets were excluded (0.62 vs $0.58 ; p=0.07$ ).

Previous meta-analyses also showed similar results that the Gail model had a satisfactory calibration and moderately acceptable discrimination [53-55]. Besides, the current study evaluated the diagnostic accuracy of the Gail model and the results showed that the sensitivity of the Gail model was poor and the results were even worse when focusing on the studies in American and European women. Accordingly, many of the breast cancer cases were misdiagnosed and this may partly explain the modest discrimination of the Gail model to some extent. Other risk factors for breast cancer such as mammographic density [83] and genetic factors [84] should be added to the Gail model in the future to provide a more accurate prediction of breast cancer. Nonetheless, few studies were combined to evaluate the diagnostic accuracy of the Gail model; more related studies are required to further confirm the results in the future.

Diagnostic meta-analysis also showed that the pooled specificity was higher in Asian women than that in American and European women, and studies with a case-control design, sample size $<1000$ and study quality $<8$ points presented a higher specificity than each of their counterparts. All studies in Asia were conducted using the hospital-based case-control design and the healthy controls were prone to have fewer risk factors than the cases. For example, biopsy is required for breast cancer cases, but is rarely used in healthy women in Asia; this may lead to lower prediction of risk in controls according to the Gail model and may increase the true negative rate and the specificity value. Moreover, most of the case-control studies were conducted with smaller sample sizes and lower study quality, and thus the difference in these subgroups may be partly explained by the distorted distribution of the case-control studies.
Additionally, Deeks' funnel plot showed publication bias exists in Chinese studies, some studies with small sample size and lower DOR may not be published, and the diagnostic accuracy of the Gail model may be overestimated to some extent. Sensitivity analysis showed that when excluding studies conducted in Chinese, the pooled specificity of the Gail model was not significantly altered but the pooled sensitivity and DOR were markedly decreased.

\section{Limitations}

The current study detected substantial heterogeneities across the studies for the three statistics that we summarized; these heterogeneities can be partially explained, but could not be markedly diminished by different geographic regions and various versions of the Gail model. Secondly, although many studies tried to evaluate the performance of different versions of the Gail model, they could not be included in this meta-analysis as they did not provide necessary indexes of the E/O ratio or the AUC with $95 \%$ CIs $[85,86]$. This limits the power of this meta-analysis to evaluate the performance of different versions of the Gail model. Thirdly, most of the included studies did not clarify which version of Gail model 2 was utilized in their studies. In the current meta-analysis, the American and European studies who cited Constantino et al.'s paper [12] and the Asian studies which were published before the AsianAmerican Gail model was developed [8] were all deemed to be Caucasian-American Gail model 2. This may lead to misclassification to some extent and may partly affect the precision of the results. Finally, in order to comprehensively evaluate the performance of the Gail model in China, the WANFANG, VIP and CNKI databases were searched, which may partly overestimate the diagnostic accuracy of the Gail model, although it has no significant effect on the Gail model's calibration and discrimination.

\section{Conclusions}

Although the original Gail model 1 and the CaucasianAmerican Gail model had a well-fitting calibration in American and European women, the Caucasian-American and Asian-American Gail models may overestimate the risk in Asian females about two times. Moreover, the discrimination and diagnostic accuracy of the Gail model were not satisfactory overall or stratified by geographic region and different versions of the Gail model. Accordingly, the Gail model was appropriate for predicting the incidence of breast cancer in American and European women, but not suitable for use in Asian women. Furthermore, this model cannot tell a woman whether she will or will not develop breast cancer precisely. Even so, it is still very valuable for women to have a well-calibrated risk assessment and select different prevention strategies that are suitable for their risk level. 


\section{Additional files}

Additional file 1: Shows sensitivity analysis (A), cumulative meta-analysis ranked by publication year $(B)$ and sample size $(C)$ of the calibration of the Gail model. (PDF 1593 kb)

Additional file 2: Shows funnel plot of calibration of the Gail model (shows) and funnel plot adjusted by trim-and-fill method (B). (PDF 255 kb)

Additional file 3: Shows subgroup analysis of calibration of the Gail model. (PDF $103 \mathrm{~kb}$ )

Additional file 4: Shows funnel plot of calibration of the Gail model when stratified by geographic region in America (A), Europe (B) and Asia (C). (PDF $305 \mathrm{~kb}$ )

Additional file 5: Shows forest plot of calibration of the Asian-American version of Gail model 2 in Asian females and Caucasian-American Gail model 2 in American, Asian and European women. (PDF 663 kb)

Additional file 6: Shows forest plot (A), sensitivity analysis (B) and cumulative analysis ranked by publication year (C) and sample size (D) of calibration of the Gail model after excluding studies conducted in Asian women. (PDF $1202 \mathrm{~kb}$ )

Additional file 7: Shows pooled E/O ratio for Gail model 1 and Caucasian-American Gail model 2 after excluding studies conducted in Asian women. (PDF $582 \mathrm{~kb}$ )

Additional file 8: Shows subgroup analysis of calibration of the Gail model after excluding studies conducted in Asian women. (PDF $106 \mathrm{~kb}$ )

Additional file 9: Shows sensitivity analysis (A), cumulative meta-analysis ranked by publication year (B) and sample size (C) of discrimination of the Gail model. (PDF 1321 kb)

Additional file 10: Shows subgroup analysis of discrimination of the Gail model. (PDF 104 kb)

Additional file 11: Shows funnel plot of discrimination of the Gail model (A) and funnel plot adjusted by trim-and-fill method (B). (PDF $226 \mathrm{~kb}$ )

Additional file 12: Shows funnel plot of discrimination of the Gail model when stratified by geographic region in America (A), Europe and others (B) and Asia (C). (PDF $278 \mathrm{~kb}$ )

Additional file 13: Shows pooled AUC for Caucasian-American Gail model 2 in American, Asian and European women and Gail model 1 in American and European women and Asian females. (PDF 686 kb)

Additional file 14: Shows Deeks' funnel plot of diagnostic accuracy meta-analysis (A) and funnel plot of stratified analysis in America and Europe (B) and Asia (C). (PDF 294 kb)

Additional file 15: Shows pooled sensitivity, specificity and DOR of Gail model 1 (A) and Gail model 2 (B). (PDF 994 kb)

Additional file 16: Shows pooled sensitivity, specificity and DOR of the Caucasian-American Gail model in American and European women (A) and Asian females (B). (PDF $828 \mathrm{~kb}$ )

Additional file 17: Shows subgroup analysis of diagnostic accuracy of the Gail model. (PDF 376 kb)

Additional file 18: Shows calibration (A) and discrimination (B) of different versions of the Gail model after excluding studies published in Chinese. (PDF $531 \mathrm{~kb}$ )

Additional file 19: Shows pooled sensitivity, specificity and DOR of Gail model 1 and Caucasian-American Gail model 2 after excluding studies published in Chinese. (PDF $888 \mathrm{~kb}$ )

\section{Abbreviations}

AUC: Area under the curve; BCRAT: Breast Cancer Risk Assessment Tool; $\mathrm{Cl}$ : Confidence interval; CNKI: China National Knowledge Infrastructure; C-statistic: Concordance statistic; DOR: Diagnostic odds ratio; E/O: Expectedto-observed ratio; FN: False negative; FP: False positive; MeSH: Medical subject headings; NOS: Newcastle-Ottawa Scale; QUADAS: Quality Assessment Diagnostic Accuracy Studies; RIS: Required information size; SEER: Surveillance Epidemiology and End Results; TN: True negative; TP: True positive; TSA: Trial sequential analysis

\section{Acknowledgements}

The authors thank Professor Hong Zheng, Xiangchun Li, Qiang Zhang, Ping Cui, Hao Chen, Huijun Yang, and Qinghua Wang who provided suggestions for editing this manuscript and they thank Juatina Ucheojor Onwuka for the language polishing work.

\section{Funding}

This work was funded by China Postdoctoral Science Foundation Grant (2017 M621091), The Doctor Start-up Grant of Tianjin Medical University Cancer Institute and Hospital (B1612), National Natural Science Foundation of China (Grants 81473039 and 81502476), Chinese National Key Scientific and Technological Project (Grants 2014BAI09B09), The Science \& Technology Development Fund of Tianjin Education Commission for Higher Education (No. 20140141), and in part by the Program for Changjiang Scholars and Innovative Research Team in University in China (IRT_14R40) and Tianjin Municipal Key Health Research Program grant 15KG143.

\section{Availability of data and materials}

All data analyzed during this study included in this published article and its additional files can be found online (http://pan.baidu.com/s/1jlkWTwU).

\section{Authors' contributions}

XW designed the study, conducted the literature search, analyzed the data and drafted the manuscript. YH conducted the literature search and revised the manuscript. $L L$ and HD extracted the data, conducted the statistical analysis and revised the manuscript. FS and KC supervised the study procedure and revised the manuscript. All authors read and approved the final manuscript. The tables and figures in the paper are original for this article and the authors have permission to use them.

Ethics approval and consent to participate

Not applicable.

\section{Consent for publication}

Not applicable.

\section{Competing interests}

The authors declare that they have no competing interests.

\section{Publisher's Note}

Springer Nature remains neutral with regard to jurisdictional claims in published maps and institutional affiliations.

Received: 8 June 2017 Accepted: 26 February 2018

Published online: 13 March 2018

\section{References}

1. GLOBOCAN: Estimated Cancer Incidence, Mortality and Prevalence Worldwide in 2012. http://globocan.iarc.fr/Pages/summary_table_pop_sel. aspx. Accessed 31 Jun 2017.

2. Breast Cancer Risk Assessment Tool. National Cancer Institute. 2011. https:// www.cancer.gov/bcrisktool/. Accessed 13 Aug 2017.

3. Gail MH, Brinton LA, Byar DP, et al. Projecting individualized probabilities of developing breast cancer for white females who are being examined annually. J Natl Cancer Inst. 1989:81:1879-86.

4. Anderson SJ, Ahnn S, Duff K. NSABP Breast Cancer Prevention Trial risk assessment program, version 2. NSABP Biostatistical Center Technical Report. 1992.

5. Fisher B, Costantino JP. Wickerham DL, et al. Tamoxifen for prevention of breast cancer: report of the National Surgical Adjuvant Breast and Bowel Project P-1 Study. J Natl Cancer Inst. 1998:90:1371-88.

6. Vogel VG, Costantino JP, Wickerham DL, et al. Effects of tamoxifen vs raloxifene on the risk of developing invasive breast cancer and other disease outcomes: the NSABP Study of Tamoxifen and Raloxifene (STAR) P-2 trial. JAMA. 2006;295:2727-41.

7. Gail MHCJ, Pee D, Bondy $\mathrm{M}$, et al. Projecting individualized absolute invasive breast cancer risk in African American women. J Natl Cancer Inst. 2007;99: 1782-92.

8. Matsuno RK, Costantino JP, Ziegler RG, et al. Projecting individualized absolute invasive breast cancer risk in Asian and Pacific Islander American women. J Natl Cancer Inst. 2011;103:951-61. 
9. Bondy $\mathrm{ML}$, Lustbader ED, Halabi S, et al. Validation of a breast cancer risk assessment model in women with a positive family history. J Natl Cancer Inst. 1994;86:620-5.

10. Spiegelman D, Colditz GA, Hunter D, Hertzmark E. Validation of the Gail et al. model for predicting individual breast cancer risk. J Natl Cancer Inst. 1994:86:600-7.

11. Rockhill B, Spiegelman D, Byrne C, et al. Validation of the Gail et al. model of breast cancer risk prediction and implications for chemoprevention. J Natl Cancer Inst. 2001;93:358-66.

12. Costantino JP, Gail MH, Pee D, et al. Validation studies for models projecting the risk of invasive and total breast cancer incidence. J Natl Cancer Inst. 1999;91:1541-8.

13. Bernatsky S, Clarke A, Ramsey-Goldman R, et al. Hormonal exposures and breast cancer in a sample of women with systemic lupus erythematosus. Rheumatology. 2004;43:1178-81.

14. Olson JE, Sellers TA, Iturria SJ, Hartmann LC. Bilateral oophorectomy and breast cancer risk reduction among women with a family history. Cancer Detect Prev. 2004;28:357-60.

15. Tice JA, Cummings SR, Smith-Bindman $R$, et al. Using clinical factors and mammographic breast density to estimate breast cancer risk: development and validation of a new predictive model. Ann Intern Med. 2008;148:337-47.

16. Schonfeld SJ, Pee D, Greenlee RT, et al. Effect of changing breast cancer incidence rates on the calibration of the Gail model. J Clin Oncol. 2010;28: 2411-7.

17. Tarabishy $Y$, Hartmann LC, Frost MH, et al. Performance of the Gail model in individual women with benign breast disease. ASCO Annual Meeting Proceedings. 2011;29(Suppl 15):1525.

18. Powell M, Jamshidian F, Cheyne K, Nititham J, Prebil LA, Ereman R. Assessing breast cancer risk models in Marin County, a population with high rates of delayed childbirth. Clin Breast Cancer. 2014;14:212-20. e211

19. McCarthy AM, Keller B, Kontos D, et al. The use of the Gail model, body mass index and SNPS to predict breast cancer among women with abnormal (BI-RADS 4) mammograms. Breast Cancer Res. 2015;17:1.

20. Schonberg MA, Li WW, Eliassen AH, et al. Performance of the Breast Cancer Risk Assessment Tool among women age 75 years and older. J Natl Cancer Inst. 2015;108(3). https://doi.org/10.1093/jnci/djv348. https://www.ncbi.nlm. nih.gov/pubmed/?term=Performance+of+the+Breast+Cancer+Risk +Assessment+Tool+among+women+age+75+years+and+older

21. Tice JA, Cummings SR, Ziv E, Kerlikowske K. Mammographic breast density and the Gail model for breast cancer risk prediction in a screening population. Breast Cancer Res Treat. 2005;94:115-22.

22. Vacek PM, Skelly JM, Geller BM. Breast cancer risk assessment in women aged 70 and older. Breast Cancer Res Treat. 2011;130:291-9.

23. Quante AS, Whittemore AS, Shriver $T$, et al. Breast cancer risk assessment across the risk continuum: genetic and nongenetic risk factors contributing to differential model performance. Breast Cancer Res. 2012;14:R144

24. Rosner BA, Colditz GA, Hankinson SE, et al. Validation of Rosner-Colditz breast cancer incidence model using an independent data set, the California Teachers Study. Breast Cancer Res Treat. 2013;142:187-202.

25. Weik JL, Lum SS, Esquivel PA, et al. The Gail model predicts breast cancer in women with suspicious radiographic lesions. Am J Surg. 2005;190:526-9.

26. Adams-Campbell LL, Makambi KH, Palmer JR, Rosenberg L. Diagnostic accuracy of the Gail model in the Black Women's Health Study. Breast J. 2007;13:332-6

27. Banegas MP, Gail MH, LaCroix A, et al. Evaluating breast cancer risk projections for Hispanic women. Breast Cancer Res Treat. 2012;132:347-53.

28. Boyle P, Mezzetti M, La Vecchia $C$, et al. Contribution of three components to individual cancer risk predicting breast cancer risk in Italy. Eur J Cancer Prev. 2004;13:183-91.

29. Decarli A, Calza S, Masala G, Specchia C, Palli D, Gail MH. Gail model for prediction of absolute risk of invasive breast cancer: independent evaluation in the Florence-European Prospective Investigation Into Cancer and Nutrition cohort. J Natl Cancer Inst. 2006;98:1686-93.

30. Amir E, Evans DG, Shenton A, et al. Evaluation of breast cancer risk assessment packages in the family history evaluation and screening programme. J Med Genet. 2003;40:807-14

31. Chlebowski RT, Anderson GL, Lane DS, et al. Predicting risk of breast cancer in postmenopausal women by hormone receptor status. J Natl Cancer Inst. 2007;99:1695-705.
32. Pastor-Barriuso R, Ascunce N, Ederra M, et al. Recalibration of the Gail mode for predicting invasive breast cancer risk in Spanish women: a populationbased cohort study. Breast Cancer Res Treat. 2013;138:249-59.

33. Buron $\mathrm{A}$, Vernet $\mathrm{M}$, Roman $\mathrm{M}$, et al. Can the Gail model increase the predictive value of a positive mammogram in a European population screening setting? Results from a Spanish cohort. Breast. 2013;22:83-8.

34. Dartois L, Gauthier E, Heitzmann J, et al. A comparison between different prediction models for invasive breast cancer occurrence in the French E3N cohort. Breast Cancer Res Treat. 2015;150:415-26.

35. Brentnall AR, Harkness EF, Astley SM, et al. Mammographic density adds accuracy to both the Tyrer-Cuzick and Gail breast cancer risk models in a prospective UK screening cohort. Breast Cancer Res. 2015;17:147.

36. Crispo A, D'Aiuto G, De Marco M, et al. Gail model risk factors: impact of adding an extended family history for breast cancer. Breast J. 2008, $14: 221-7$

37. Ulusoy C, Kepenekci I, Kose K, Aydintug S, Cam R. Applicability of the Gail model for breast cancer risk assessment in Turkish female population and evaluation of breastfeeding as a risk factor. Breast Cancer Res Treat. 2010; 120:419-24.

38. Chay WY, Ong WS, Tan PH, et al. Validation of the Gail model for predicting individual breast cancer risk in a prospective nationwide study of 28,104 Singapore women. Breast Cancer Res. 2012;14:R19.

39. Hu JY. Research on the applicability of Gail model in the assessment of breast cancer risk in Zhejiang eastern coastal women. Zhejiang University Medical College; 2015. http://kns.cnki.net/KCMS/detail/detail.aspx?dbcode=CMFD\&dbname=CMFD2 01502\&filename=1015614713.nh\&uid=WEEvREcwSIJHSIdRa1Fhb09jSnZpZOpoVEN nSEttRElqTVFNQXBUczBDVT0=\$9A4hF_YAuvQ5obgVAgNKPCYCEjKensW4ggl8Fm 4gTkoUKalD8j8gFw!!\&v=MjU4ODFYMUx1eFITNORoMVQzcVRyV00xRnJDWJMS2Za T1ptRnl2a1VyM09WRj|2RzdXNUd0Yk5ySkViUEISOGU=

40. Anothaisintawee T, Thakkinstian A, Wiratkapun C, et al. Developing and validating risk prediction model for screening breast cancer in Thai women. Eur J Epidemiol. 2013;28(Suppl 1):96-7.

41. Min JW, Chang MC, Lee HK, et al. Validation of risk assessment models for predicting the incidence of breast cancer in Korean women. J Breast Cancer. 2014;17:226-35.

42. Pan $X P$, Jin $X$, Ding $H$, et al. Preliminary study on risk evaluation model of breast cancer in Beijing and Guangdong. Matern Child Health Care of China. 2009;11:1469-71.

43. Liu LY. A pilot study on risk factors and risk assessment score screening model for high-risk population of breast cancer. Shandong University; 2010 http://g.wanfangdata.com.cn/details/detail.do?_type=degree\&id=Y1793588.

44. Wang Y, Xu L, Shen CJ, et al. Clinical application of Gail model in the assessment of breast cancer risk. Int J Pathol Clin Med. 2010:6:473-5.

45. Duan XK, Luo ZY, Chen L, et al. The application of the Gail breast cancer prediction model in Chinese women. Matern Child Health Care of China. 2014;28:4667-9.

46. Rong L, Li H, Wang EL. To establish the breast cancer risk prediction model for women in Shenzhen in China. Matern Child Health Care of China. 2016; 3:470-3.

47. Li JM, Wang W, Li SY. Elementary study on application of Gail model breast cancer risk assessment tool. China Modern Med. 2009;14:40-1.

48. Zhou JJ, Wang YJ, Gao SN, et al. Application of Gail model for assessment on breast cancer risk. Shanghai J Prev Med. 2014;5:236-9.

49. Huang $\mathrm{JH}$. Application of the Gail prediction model for breast cancer in the community. Chin Foreign Med Res. 2015;35:151-2

50. An LY, Zhang KZ, Zhang $Y L$, et al. To explore the application of the Gail and Cuzick-Tyrer breast cancer prediction model. Matern Child Health Care of China. 2016:5:945-6.

51. Dite GS, Mahmoodi M, Bickerstaffe A, et al. Using SNP genotypes to improve the discrimination of a simple breast cancer risk prediction model. Breast Cancer Res Treat. 2013;139:887-96.

52. Maclnnis R, Dite G, Bickerstaffe A, et al. Validation study of risk prediction models for female relatives of Australian women with breast cancer. Hered Cancer Clin Pract. 2012;10(Suppl 2). https://www.embase.com/search/ results? subaction=viewrecord\&rid $=1$ \&page $=1 \& \mathrm{id}=\mathrm{L} 70928745$.

53. Anothaisintawee T, Teerawattananon Y, Wiratkapun C, et al. Risk prediction models of breast cancer: a systematic review of model performances. Breast Cancer Res Treat. 2012;133:1-10.

54. Meads C, Ahmed I, Riley RD. A systematic review of breast cancer incidence risk prediction models with meta-analysis of their performance. Breast Cancer Res Treat. 2012;132:365-77. 
55. Nelson HD, Pappas M, Zakher B, et al. Risk assessment, genetic counseling, and genetic testing for BRCA-related cancer in women: a systematic review to update the U.S. Preventive Services Task Force recommendation. Ann Intern Med. 2014;160:255-66.

56. Wetterslev J, Thorlund K, Brok J, Gluud C. Trial sequential analysis may establish when firm evidence is reached in cumulative meta-analysis. J Clin Epidemiol. 2008;61:64-75.

57. Wetterslev J, Thorlund K, Brok J, Gluud C. Estimating required information size by quantifying diversity in random-effects model meta-analyses. BMC Med Res Methodol. 2009;9:86.

58. Stroup DF, Berlin JA, Morton SC, et al. Meta-analysis of observational studies in epidemiology: a proposal for reporting. Meta-analysis Of Observational Studies in Epidemiology (MOOSE) group. JAMA. 2000;283:2008-12.

59. WANFANG database. http://www.wanfangdata.com.cn/. Accessed 31 Jul 2016.

60. VIP database. http://www.cqvip.com/. Accessed 31 Jul 2016.

61. China National Knowledge Infrastructure database. http://www.cnki.net/. Accessed 31 Jul 2016.

62. Pankratz VS, Hartmann LC, Degnim AC, et al. Assessment of the accuracy of the Gail model in women with atypical hyperplasia. J Clin Oncol. 2008;26: 5374-9

63. McKian KP, Reynolds CA, Visscher DW, et al. Novel breast tissue feature strongly associated with risk of breast cancer. J Clin Oncol. 2009;27:5893-8.

64. Mealiffe ME, Stokowski RP, Rhees BK, et al. Assessment of clinical validity of a breast cancer risk model combining genetic and clinical information. J Natl Cancer Inst. 2010;102:1618-27.

65. Dite GS, Maclnnis RJ, Bickerstaffe A, et al. Breast cancer risk prediction using clinical models and 77 independent risk-associated SNPs for women aged under 50 years: Australian Breast Cancer Family Registry. Cancer Epidemiol Biomarkers Prev. 2016;25:359-65.

66. Pankratz VS, Degnim AC, Frank RD, et al. Model for individualized prediction of breast cancer risk after a benign breast biopsy. J Clin Oncol. 2015;33:923-9.

67. Allman R, Dite GS, Hopper JL, et al. SNPs and breast cancer risk prediction for African American and Hispanic women. Breast Cancer Res Treat. 2015; 154:583-9.

68. Stang A. Critical evaluation of the Newcastle-Ottawa scale for the assessment of the quality of nonrandomized studies in meta-analyses. Eur J Epidemiol. 2010:25:603-5.

69. Whiting P, Rutjes AW, Reitsma JB, et al. The development of QUADAS: a tool for the quality assessment of studies of diagnostic accuracy included in systematic reviews. BMC Med Res Methodol. 2003;3:25.

70. DerSimonian R, Laird N. Meta-analysis in clinical trials. Control Clin Trials. 1986;7:177-88

71. Thakkinstian A, McElduff P, D'Este C, et al. A method for meta-analysis of molecular association studies. Stat Med. 2005;24:1291-306.

72. Mullen B, Muellerleile P, Bryant B. Cumulative meta-analysis: a consideration of indicators of sufficiency and stability. Pers Soc Psychol Bull. 2001;27:1450-62.

73. Begg CB. Publication bias: a problem in interpreting medical data. JR Statist Soc A. 1988;151:419-63.

74. Duval S, Tweedie R. Trim and fill: a simple funnel-plot-based method of testing and adjusting for publication bias in meta-analysis. Biometrics. 2000; 56:455-63.

75. Egger M, Davey Smith G, Schneider M, Minder C. Bias in meta-analysis detected by a simple, graphical test. BMJ. 1997:315:629-34.

76. Reitsma JB, Glas AS, Rutjes AW, Scholten RJ, Bossuyt PM, Zwinderman AH. Bivariate analysis of sensitivity and specificity produces informative summary measures in diagnostic reviews. J Clin Epidemiol. 2005;58:982-90.

77. Deeks JJ, Macaskill P, Irwig L. The performance of tests of publication bias and other sample size effects in systematic reviews of diagnostic test accuracy was assessed. J Clin Epidemiol. 2005;58:882-93.

78. Thorlund K, Wetterslev J, Brok J, et al. User manual for trial sequential analysis (TSA). Copenhagen, Denmark: Copenhagen Trial Unit, Centre for Clinical Intervention Research; 2011. p. 1-115.

79. Morabia A, Costanza MC. International variability in ages at menarche, first live birth, and menopause. World Health Organization Collaborative Study of Neoplasia and Steroid Contraceptives. Am J Epidemiol. 1998; 148:1195-205

80. Siu AL, U.S. Preventive Services Task Force. Screening for Breast Cancer: U.S. Preventive Services Task Force Recommendation Statement. Ann Intern Med. 2016;164:279-96.
81. Oeffinger KC, Fontham ET, Etzioni R, et al. Breast cancer screening for women at average risk: 2015 guideline update from the American Cancer Society. JAMA. 2015;314:1599-614.

82. Huang $Y$, Dai $H$, Song $F$, et al. Preliminary effectiveness of breast cancer screening among 1.22 million Chinese females and different cancer patterns between urban and rural women. Sci Rep. 2016;6:39459.

83. McCormack VA, dos Santos Silva I. Breast density and parenchymal patterns as markers of breast cancer risk: a meta-analysis. Cancer Epidemiol Biomarkers Prev. 2006;15:1159-69.

84. Antoniou AC, Wang X, Fredericksen ZS, et al. A locus on 19p13 modifies risk of breast cancer in BRCA1 mutation carriers and is associated with hormone receptor-negative breast cancer in the general population. Nat Genet. 2010; 42:885-92.

85. Abu-Rustum NR, Herbolsheimer $\mathrm{H}$. Breast cancer risk assessment in indigent women at a public hospital. Gynecol Oncol. 2001;81:287-90.

86. Bondy ML, Newman LA. Breast cancer risk assessment models: applicability to African-American women. Cancer. 2003:97:230-5.

\section{Submit your next manuscript to BioMed Central and we will help you at every step:}

- We accept pre-submission inquiries

- Our selector tool helps you to find the most relevant journal

- We provide round the clock customer support

- Convenient online submission

- Thorough peer review

- Inclusion in PubMed and all major indexing services

- Maximum visibility for your research

Submit your manuscript at www.biomedcentral.com/submit
) Biomed Central 